\title{
Malaria in West Cameroon: An Assessment of the Populations' Knowledge, Attitudes and Practices
}

\author{
Eric Defo Tamgno ${ }^{1,2, *}$, Armand Tiotsia Tsapi ${ }^{2,3}$, Martin Fossi ${ }^{4}$, \\ Ghyslaine Bruna Djeunang Dongho ${ }^{2,5}$, Dorothy Kah Fosah Achu ${ }^{6}$, Germaine Ekoyol Ekobe \\ Gianluca Russo $^{3}$, Olivier Ethgen ${ }^{1}$, Martin Sanou Sobze ${ }^{7}$ \\ ${ }^{1}$ Department of Public Health, Epidemiology and Health Economics, University of Liege, Liege, Belgium \\ ${ }^{2}$ Faculty of Sciences and Technology, Evangelical University of Cameroon, Bandjoun, Cameroon \\ ${ }^{3}$ Department of Infectious Diseases, Microbiology and Public Health, The Sapienza University of Rome, Rome, Italy \\ ${ }^{4}$ Departmentof Medicine, University of Liege, Liege, Belgium \\ ${ }^{5}$ Laboratory of Immunogenetics, National Institute of Allergies and Infectious Diseases, National Institutes of Health, Bethesda, USA \\ ${ }^{6}$ National Malaria Control Program (NMCP), Ministry of Public Health, Yaounde, Cameroon \\ ${ }^{7}$ Faculty of Medicine and Pharmaceutical Sciences, University of Dschang, Dschang, Cameroon
}

\section{Email address:}

defo2008@yahoo.fr (E. D. Tamgno)

${ }^{*}$ Corresponding author

\section{To cite this article:}

Eric Defo Tamgno, Armand Tiotsia Tsapi, Martin Fossi, Ghyslaine Bruna Djeunang Dongho, Dorothy Kah Fosah Achu, Germaine Ekoyol Ekobe, Gianluca Russo, Olivier Ethgen, Martin Sanou Sobze. Malaria in West Cameroon: An Assessment of the Populations' Knowledge, Attitudes and Practices. Central African Journal of Public Health. Vol. 7, No. 2, 2021, pp. 47-52. doi: 10.11648/j.cajph.20210702.11

Received: February 15, 2021; Accepted: March 2, 2021; Published: March 12, 2021

\begin{abstract}
Background: Malaria remains one of the main causes of morbidity and mortality in Cameroon. Children under 5 years old and pregnant women are most burdened. A few studies have been carried out on the knowledge, attitudes and practices (KAP) of patients towards malaria in this country. Objective: We aimed at evaluating the level of knowledge, attitudes and practice towards malaria in Western Cameroon. Method: We conducted a cross-sectional survey, using a semiopened questionnaire in two Cameroonian's hospitals in April 2018. We analyzed our collected data with Chi square test through SAS software (version 9.4). P-values lower than 0.05 were considered statistically significant. Result: Of 691 participants, 55.14\% (381/691) defined malaria as a parasitic disease, 100\% mentioned the mosquito as the transmission vector and $89.15 \%$ (616/691) mentioned blood stream as transmission route. The most preventive method used by the participants was mosquito nets. The use of malaria treatment was associated with the level of income and the fact of consultation of a health care practitioner the month preceding the survey. About 72.4\% (501/691) of respondents took antimalarial treatment without consultation or medical prescription. Among patients who spent less than 8000XAF (12Euro) for treatment during their last episode of malaria, 70.1\% (101/144) used a plant-based treatment. Conclusion: Participants had good knowledge and attitudes towards malaria. However, practices were not the best. These results highlight the problem of self-medication, which might lead to some resistance against antimalarial treatment in the future.
\end{abstract}

Keywords: Knowledge, Attitudes and Practices, Self-medication, Malaria, West-Cameroon

\section{Introduction}

Malaria is a public health concern around the world. It is one of the leading causes of mortality and morbidity in subSaharan Africa. In 2019, the World Health Organization (WHO) recorded about 229 million cases of malaria worldwide (94\% of all cases recorded in Africa Region), of which there were 409,000 deaths ( $94 \%$ of deaths registered in Africa Region). [1] In the same year, the WHO reported 274,030 deaths of children under 5 years of age (about $67 \%$ 
of deaths in all age groups). [1] Indeed, some groups have an increased risk of being infected with malaria; these include children under 5 years old and pregnant women. [2] Cameroon is a malaria endemic country. It is located in Central Africa between the end of the Sahara in the North and the beginning of the equatorial forest in the South. In Cameroon, Malaria is the leading cause of death and morbidity among pregnant women and children under 5 years old. [3] The Ministry of Public Health of Cameroon reported $8,294,473$ individuals coming for consultation in healthcare facilities in 2018, 1,934,876 cases of malaria were recorded, representing an attributed morbidity rate of $25.8 \%$ [4] About 22,813 deaths recorded with $3263=$ malaria-related, representing a mortality rate of $14.3 \%$. [4] Moreover, malaria alone is responsible for $26 \%$ of absences in the workplace and $40 \%$ of household health expenditure. [5]

Many control strategies were put in place by WHO and Governments. Despite these innovative and cost-effective strategies, malaria persists, because the lack of knowledge, inappropriate attitudes and practices towards the disease increase the number of malaria cases. [6] Community participation and community knowledge, attitude, behavior and practices, play an important role in the successful implementation of malaria control programs. [6] In Cameroon, a few studies were carried out on the knowledge, attitudes and practices (KAP) of patients in relation with malaria. [7-12] None of them assessed the West region of Cameroon. Hence our goal is to assess the KAP towards malaria among patients of Western Cameroon.

\section{Materials and Methods}

We conducted a cross-sectional analytical study, through a semi-opened questionnaire, in two hospitals of the western region of Cameroon, Dschang District Hospital in Dschang and the Mbouo Protestant Hospital in Bandjoun. The questionnaire was structured to answer questions about participants' socio-demographic characteristics, knowledge, attitudes and practices towards malaria. Data collection took place in April 2018 and involved all patients seeking for consultation for malaria-related symptoms in each of the two above-mentioned hospitals. We included patients aged at least 18 years old, and who gave their informed consent. The calculation of the sample size according to Lwanga \& Lemeshow, 1991, allowed us to obtain a minimum sample size of 588 people. Anticipating a 10\% non-response rate, we set our target to 647participants [13].

Before the analysis, the data was encoded in Microsoft Excel software version 2007 and exported to the SAS software (version 9.4) for analyses. Chi square test were used. P-values lower than 0.05 were considered statistically significant.

\section{Results}

\subsection{Socio-demographic Data}

During the study, 760 patients fulfilled the inclusion criteria, 691 respondents agreed to participate, for a response rate of $91 \%$. Participants had age ranging from 18 to 80 years and a median of age of 24 years (Table 1A). Female gender $(53.4 \% ; 369 / 691)$ and French-speaking $(88.6 \%, 612 / 691)$ were most represented (Table 1B). Of the 691 interviewed, $76.7 \%(530 / 691)$ were single, $27.6 \%(191 / 691)$ had at least 1 child under 5 years old and $26.1 \%(180 / 691)$ had a household of at least 5 individuals (Table 1B). Concerning the profession, 53.7\% (371/691) of respondents were students and $13.6 \%(94 / / 691)$ were unemployed (Table 1B). About $74.1 \%(512 / 691)$ of respondents declared to have an income lower than 50,000central Africa CFA francs (XAF) (76 euro) (Table 1B).

Table 1. Socio-demographic variables Description. Numerical variables (A) qualitative variables (B).

\begin{tabular}{|c|c|c|c|c|c|}
\hline \multicolumn{6}{|l|}{$\mathbf{A}$} \\
\hline Variables & Frequency & mean & Median (P25-P75) & Min-Max & Shapiro-Wilk (P-Value) \\
\hline Age (year) & 691 & 29.3 & $24(21-34)$ & $18-80$ & $<0.0001$ \\
\hline \multicolumn{6}{|l|}{$\bar{B}$} \\
\hline Variables & & Modality & & Frequency & Percentage \\
\hline \multirow{2}{*}{ Sex } & & Men & & 322 & 46.6 \\
\hline & & Women & & 369 & 53.4 \\
\hline \multirow{6}{*}{ Marital status } & & Single & & 530 & 76.7 \\
\hline & & Married & & 116 & 16.8 \\
\hline & & Cohabiting & & 22 & 3.2 \\
\hline & & Widowed & & 12 & 1.7 \\
\hline & & Divorced & & 3 & 0.4 \\
\hline & & Polygamous & & 8 & 1.2 \\
\hline \multirow{2}{*}{ Language spoken } & & French & & 612 & 88.6 \\
\hline & & English & & 79 & 11.4 \\
\hline \multirow{4}{*}{ Highest level of study } & & Unschooled & & 24 & 3.5 \\
\hline & & Primary & & 65 & 9.4 \\
\hline & & Secondary & & 188 & 27.2 \\
\hline & & University & & 414 & 59.9 \\
\hline \multirow{2}{*}{\multicolumn{2}{|c|}{ At least 1 child under 5 years of age }} & Yes & & 191 & 27.6 \\
\hline & & No & & 500 & 72.4 \\
\hline
\end{tabular}




\begin{tabular}{|c|c|c|c|}
\hline \multicolumn{4}{|l|}{ B } \\
\hline Variables & Modality & Frequency & Percentage \\
\hline \multirow{2}{*}{ At least 5 people in the household } & Yes & 180 & 26.1 \\
\hline & No & 511 & 74 \\
\hline \multirow{5}{*}{ Profession } & Student & 371 & 53.7 \\
\hline & Household & 32 & 4.6 \\
\hline & Worker in the formal sector & 78 & 11.3 \\
\hline & Worker in informal sector & 116 & 16.8 \\
\hline & Unemployed & 94 & 13.6 \\
\hline \multirow{5}{*}{ Monthly income (in XAF) } & From $0-50,000(0-76$ Euro $)$ & 512 & 74.1 \\
\hline & From 50,000-100,000 (76-153 Euro) & 61 & 8.8 \\
\hline & From 100,000-150,000 (153-230 Euro) & 47 & 6.8 \\
\hline & From $150,000-200,000$ (230-306 Euro) & 26 & 3.8 \\
\hline & More than 200,000 (more than 306 Euro) & 45 & 6.5 \\
\hline
\end{tabular}

XAF, Central Africa CFA franc

\subsection{Knowledge About Malaria}

Regarding knowledge about malaria, all respondents had heard about malaria and $55.1 \%(381 / 691)$ defined malaria as a parasitic disease (Table 2). Everyone mentioned the mosquito as the transmission vector and $89.2 \%(616 / 691)$ the bloodstream as transmission route (Table 2). About $48.63 \%$ (336/691) choose the mosquito net as a means of preventing malaria and $42.3 \%(292 / 691)$ said children under 5 were the most vulnerable group (Table 2).

Table 2. Knowledge of the study population on malaria.

\begin{tabular}{|c|c|c|c|}
\hline Variables & Modality & Frequency & Percentage \\
\hline \multirow{2}{*}{ Have heard about malaria } & Yes & 691 & 100 \\
\hline & No & 0 & 0 \\
\hline \multirow{4}{*}{ Malaria definition } & Infectious disease & 212 & 30.7 \\
\hline & Parasitic disease & 381 & 55.1 \\
\hline & Cancer & 1 & 0.1 \\
\hline & Do not know & 97 & 14 \\
\hline \multirow{3}{*}{ Moment where the mosquito bite most } & Evening & 665 & 96.2 \\
\hline & During the day & 0 & 0 \\
\hline & At anytime & 26 & 3.8 \\
\hline \multirow{3}{*}{ Vector of malaria } & Mosquito & 691 & 100 \\
\hline & Fly & 0 & 0 \\
\hline & Other & 0 & 0 \\
\hline \multirow{4}{*}{ Group at risk against malaria } & Childrenunder5years & 292 & 42.3 \\
\hline & Pregnant woman & 17 & 2.5 \\
\hline & Anybody & 70 & 10.1 \\
\hline & Childrenunder5andpregnantwomen & 312 & 45.2 \\
\hline \multirow{4}{*}{ Routes of malaria transmission } & Blood & 616 & 89.2 \\
\hline & Saliva & 10 & 1.5 \\
\hline & Sexual way & 2 & 0.3 \\
\hline & Other & 63 & 9.1 \\
\hline \multirow{5}{*}{ Malaria prevention method } & Mosquito net & 336 & 48.6 \\
\hline & Insecticide & 9 & 1.3 \\
\hline & Mosquito net and insecticide & 232 & 33.6 \\
\hline & Environmental hygiene & 3 & 0.4 \\
\hline & All & 111 & 16.1 \\
\hline
\end{tabular}

\subsection{Attitudes and Practices Towards Malaria}

The analysis of attitudes and practices revealed $45.4 \%$ (314/691) of participants using mosquito nets as a preventative measure (Table 3). About 58.6\% (405/691) owned a mosquito net and, $90.1 \%$ (365/405) of them obtained their mosquito nets free of charge. A small proportion of those having mosquito nets $(8.89 \% ; 36 / 405)$ did not use them. The principal reason $(52.8 \% ; 19 / 36)$ was the sensations of heat while sleeping under. Most patients $82.2 \%(568 / 691)$ reported using only pharmacy drugs and while $17.5 \%$ (121/691) used only plant-based medicines to treat malaria (Table 3). The reason given for the use of plants was that, the plants remain accessible and cost less than the drugs sold in pharmacies. In the month prior to the survey, $27.6 \%(191 / 691)$ consulted at least once for malaria and all participants to the study used a malaria treatment at least once (Table 3). About $77.9 \%$ (538/691) said they spent between 8000 and 15,000 XAF (12 and 23 Euro) to get 
treatment during their last episode of malaria (Table 3).

Table 3. Attitudes and practices of the study population towards malaria.

\begin{tabular}{|c|c|c|c|}
\hline Variables & Modality & Frequency & Percentage \\
\hline \multirow{2}{*}{ At least one malaria consultation the previous month } & Yes & 191 & 27.6 \\
\hline & No & 500 & 72.4 \\
\hline Atleastonemalariaconsultationthe 12 monthspreceding & Yes & 413 & 59.8 \\
\hline \multirow{3}{*}{ Prevention method used } & Mosquito net & 314 & 45.4 \\
\hline & Insecticide & 229 & 33.1 \\
\hline & Environmental hygiene & 91 & 13.2 \\
\hline \multirow{2}{*}{ To have a mosquito net } & Yes & 405 & 58.6 \\
\hline & No & 286 & 41.4 \\
\hline \multirow{2}{*}{ Means of obtaining the mosquito net from those who have } & Free & 365 & 90.1 \\
\hline & Purchase & 40 & 9.9 \\
\hline \multirow{2}{*}{ Use of mosquito net among those who have it } & Yes & 369 & 91.1 \\
\hline & No & 36 & 8.9 \\
\hline \multirow{3}{*}{ Reason for not using mosquito net among those who have } & Heat & 19 & 52.8 \\
\hline & Smothering & 10 & 27.8 \\
\hline & Bad condition & 6 & 16.7 \\
\hline \multirow{3}{*}{ Type of treatment used } & Herbal medicines & 121 & 17.5 \\
\hline & Drugs sold in pharmacy & 568 & 82.2 \\
\hline & Herbal and pharmaceutical treatment & 2 & 0.3 \\
\hline \multirow{2}{*}{ Reason for use of plants among those who use it } & Low cost & 114 & 91.9 \\
\hline & The danger of chemical products & 10 & 8.1 \\
\hline \multirow{2}{*}{ Use at least 1 time of treatment the previous month } & Yes & 691 & 100 \\
\hline & No & 0 & 0 \\
\hline \multirow{3}{*}{ Cost of treatment during the preceding malaria episode (in XAF) } & From 0-8000 (0-12Euro) & 144 & 20.8 \\
\hline & From $8000-15,000$ (12-23Euro) & 538 & 77.9 \\
\hline & More than 15,000 (23Euro) & 9 & 1.3 \\
\hline
\end{tabular}

XAF, Central Africa CFA franc

\subsection{Factors Influencing Malaria Treatment Among the Study Population}

The analysis of the use of treatment compared to the consultation during the month preceding the survey shows a significant correlation (P-value $<0.05)$. And in the month preceding the survey, $72.4 \%(501 / 691)$ of respondents used treatment without prescription (Table 4).

Table 4. Comparison between the use of treatment and the consultation during the month preceding the survey.

\begin{tabular}{|c|c|c|}
\hline & $\begin{array}{l}\text { Use at least } 1 \text { time of treatment the previous } \\
\text { month (percentage) }\end{array}$ & $\begin{array}{l}\text { No treatment the previous month } \\
\text { (percentage) }\end{array}$ \\
\hline At least one malaria consultation previous month & 27.6 & 0 \\
\hline No consultation for malaria previous month & 72.4 & 0 \\
\hline Total & 100 & 0 \\
\hline Frequency & 691 & 0 \\
\hline P-value & $<0.001$ & \\
\hline
\end{tabular}

We analyzed the cost of treatment versus treatment used by respondents. There is a significant correlation (P-Value $<0.05$ ) between these two variables. The group of patients who spent less than 8000 XAF (12Euro) for treatment during their last episode of malaria, 70.1\% (101/144) used a plant-based treatment. While in the group of patients who spent more than 15,000XAF (23 Euro), 88.9\% (8/9) used drugs from pharmacies (Table 5).

Table 5. Comparison between the cost of treatment and treatment used.

\begin{tabular}{|c|c|c|c|}
\hline & $\begin{array}{l}\text { Less than 8000XAF (12 Euro) } \\
\text { (percentage) }\end{array}$ & $\begin{array}{l}\text { Between } 8000 \text { and } 15,000 \text { XAF } \\
\text { (12-23Euro) (percentage) }\end{array}$ & $\begin{array}{l}\text { More than 15,000 XAF } \\
\text { (23Euro) (percentage) }\end{array}$ \\
\hline Plants & 70.1 & 3.5 & 11.1 \\
\hline Drugs sold in pharmacy & 29.9 & 96.1 & 88.9 \\
\hline Total & 100 & 100 & 100 \\
\hline Frequency & 144 & 538 & 9 \\
\hline P-value & $<0.001$ & & \\
\hline
\end{tabular}

XAF, Central Africa CFA franc 
Finally, we analyzed the use of treatment in relation to income. It appears that income is significantly correlated (PValue $<0.05)$ with the use of treatment. Moreover, most of patients $(74.1 \%, 513 / 691)$ with an income less than 50,000 XAF (76Euro), used treatment, at least once in the month preceding the survey.

\section{Discussion}

This study focused on the assessment of knowledge, attitudes and practices of western Cameroon's patients towards malaria. Our study shows a good knowledge of malaria among the patients surveyed. Malaria endemicity coupled with efforts of the National Malaria Control Program of Cameroon makes patients familiar and more educated about the disease. This result goes in line with findings of Kimbi et al. in their study conducted in $2014,86 \%$ of participants had a good knowledge of malaria transmission route. [14] The respondents new about the most costeffective malaria prevention method, the use of mosquito nets. These results are similar to those obtained by Ndo et al. in 2011 ; where $69 \%$ reported the use of mosquito nets as malaria preventing method. [9]

Malaria attitudes and practices were not the best among the respondents. Between 2011 and 2016, the Cameroonian Government, thanks to Roll Back Malaria funding, organized two long-lasting impregnated nets (LLINs) distribution campaigns, in order to fulfill the commitment to ensure "Universal coverage of populations of LLINs". Despite the increase of LLINs use between 2013 and 2017, going from $40.4 \%$ in 2013 to $58.3 \%$ in 2017 nationwide, efforts are required for a sustainable behavioral change. [15]

Pharmacy drugs rather than herbal treatment high used could be explained by recent directives of the Ministry of Public Health of Cameroon regarding the pricing of the management of non-severe and severe malaria cases. According to these guidelines, the treatment of non-severe and severe cases of malaria is free of charge in children under 5 years old. [16] For patients over 5 years old and adults, the treatment of non-severe malaria costs between 105 and $250 \mathrm{XAF}$ (0.16 and 0.38 Euro) while that of severe malaria costs 8000 XAF (12Euro) and 4000 XAF (6Euro) for pregnant women. [16, 17] Thus, pharmacy drugs are affordable and reduce the solicitation of other therapeutic itineraries.

Despite these guidelines, plant-based treatments are still used because they are significantly cheaper than pharmacy drugs. The same reason was mentioned in studies carried out by Willcox et al., and Getachew et al. [18, 19] A supportive argument to this cost-related issue is that the group of patients who spent less than 8000 XAF (12Euro) during their last episode of malaria, prioritized plant-based treatments, while those who spent more than 15,000 XAF (23 Euro) during their last episode of malaria preferred pharmacy drugs.

All patients reported at least one malaria treatment within the month prior to the survey, and most of them have low income. Interestingly, this result does not correlate unpublished results reporting $50 \%$ of patients from the Dschang District Hospital who did not take antimalarial drugs 6 months prior to the survey. This could imply that having a low income is a factor favoring malaria infection and hence the need for treatment. Still, we should consider the common confusion of fever as malaria, and antipyretics as antimalarial drugs.

Self-medication appeared as a recurrent issue. This was raised by Pouhé et al. in 2011. They highlighted selfmedication as the first reflex in illness in Cameroon and more than half of the population use antimalarial drugs systematically. [20] The justifications most often mentioned are the high cost of care for patients in healthcare facilities, the low purchasing power, the avidity of some pharmacists who do not respect the rules for dispensing medicines. [21] According to Chiribagula et al. (2015), the main risks associated with self-medication include microbial resistance to drugs, drug accidents, nonbeneficial drug interactions, drug dependence, and substance abuse. [21]

\section{Conclusion}

The main purpose of our study was to assess KAPs towards malaria of patients of the western Cameroon. We noted a good level of knowledge on malaria. Attitudes and practices were less good, especially self - medication which hides several consequences including drug resistance. Moreover, plant-based drugs usage was related to the purchase power of patients.

It is important to raise awareness about good attitudes and practices towards malaria, but also about self-medication and its consequences.

\section{Limits}

In this study, we noted as main limitation in the site which was hospital environments. The representativeness in relation to the general population is doubtful especially if we consider that people tend to come to the hospital when they face critical health situations. It was a convenient decision, given the limited resources. Another limitation could be a selection bias related the inclusion criteria, coming to consultation for malaria-related symptoms. Then we needed the help of the practitioners to select participants.

\section{Conflict of Interests}

The authors declare that they do not have any conflict of interest.

\section{Funding}

This work did not receive funding. 


\section{Ethical Approval}

Prior to the beginning of the study, we obtained the approval of the National Committee of Ethics and Research in Human Sciences of Cameroon, $\mathrm{N}^{\circ}$ : 2018/05/1025/CE/CNERSH/SP.

\section{Acknowledgements}

The authors would like to express their gratitude to all study participants for their cooperation, clinical staff for their support, and local authorities for permission to conduct this research.

\section{References}

[1] World malaria report 2020: 20 years of global progress and challenges. Geneva: World Health Organization; 2020. Licence: CC BY-NC-SA 3.0 IGO.

[2] Organisation Mondiale de la Santé. Paludisme. 2020. Available from: https:/www.who.int/fr/news-room/factsheets/detail/malaria.

[3] Christian J, Barrère M. Situation Du Paludisme Et Stratégies De Lutte Contre Le Paludisme $\mathrm{Au}$ Cameroun. Paludisme. 2002; 165-78.

[4] Programme National de Lutte contre le paludisme C. Surveillance du paludisme en 2018. 2018.

[5] Ministère de la Santé du Cameroun : lancement officiel de la distribution gratuite de plus de 2,3 millions de moustiquaires dans la région du Centre | MINSANTE. 2016. Available from: http://www.minsante.cm/site/?q=en/node/550.

[6] Haq S SR, S H, RC D. Studies on Knowledge, Attitude and Practices in Malaria Endemic Tribal Areas of Bihar and Jharkhand, India. J Trop Dis. 2013 Jul 17; 01 (03): 1-6. Available from: http://www.esciencecentral.org/journals/studies-onknowledge-attitude-and-practices-in-malaria-endemic-tribalareas-of-bihar-and-jharkhand-india-2329891X.1000110.php?aid=17047.

[7] Moyou-Somo R, Essomba P, Songue E, Tchoubou NN, Ntambo A, Hiol HN, et al. A public private partnership to fight against malaria along the Chad-Cameroon pipeline corridor: I. Baseline data on socio-anthropological aspects, knowledge, attitudes and practices of the population concerning malaria. BMC Public Health. 2013.

[8] Nsagha DS, Njunda AL, Kamga HLF, Nsagha SM, Assob JCN, Wiysonge CS, et al. Knowledge and practices relating to malaria in a semi-urban area of Cameroon: Choices and sources of antimalarials, self-treatment and resistance. Pan Afr Med J. 2011.
[9] Ndo C, Menze-Djantio B, Antonio-Nkondjio C. Awareness, attitudes and prevention of malaria in the cities of Douala and Yaoundé (Cameroon). Parasites and Vectors. 2011.

[10] Nkuo Akenji TK, Ntonifor NN, Ching JK, Kimbi HK, Ndamukong KN, Anong DN, et al. Evaluating a malaria intervention strategy using knowledge, practices and coverage surveys in rural Bolifamba, southwest Cameroon. Trans R Soc Trop Med Hyg. 2005.

[11] Shey N D, Clement AN J, N M, Wung B A, Ivo K K. Community Health Workers' Knowledge, Attitudes and Practices Regarding Malaria Control and Prevention in Bamenda, Cameroon: A Community Based Study. J Heal Med Informatics. 2017; $08 \quad$ (05). Available from: https://www.omicsonline.org/open-access/community-healthworkers8217-knowledge-attitudes-and-practices-regardingmalaria-control-and-prevention-in-bamenda-cameroon-acomm-2157-7420-1000294-96347.html.

[12] Kojom L, Lehman L. Knowledge and Beliefs towards Malaria and Associated Factors among Residents of the Town of Douala, Cameroon. Arch Curr Res Int. 2018; 14 (3): 1-17. Available from: http://www.sciencedomain.org/abstract/25735.

[13] Lwanga SK. Determination De La Taille D ' Un Echantillon Sanometriques. Oms. 1991; 90.

[14] Institut National de la Statistique du Cameroun. Quatrieme enquete Camerounaise auprès des ménages (ECAM4). Yaounde. 2015; 1-63.

[15] PNLP C. Rapport Annuel 2017 du PNLP. YAOUNDE; 2017. p. 65.

[16] Ministère de la santé publique. Décision fixant le prix de la combinaison artesunate-amodiaquine destinés aux jeunes de plus de cinq ans et adultes au Cameroun. 2011.

[17] Ministère de la santé publique. Décision poertant tarification de la prise en charge du paludisme au Cameroun. 2014.

[18] Alebie G, Urga B, Worku A. Systematic review on traditional medicinal plants used for the treatment of malaria in Ethiopia : trends and perspectives. Malar J. 2017; 1-13.

[19] Willcox ML, Bodeker G. Traditional herbal medicines for malaria Clinical review. 2004.

[20] Pouhè Nkoma P. Itinéraires thérapeutiques des malades au Cameroun: les déterminants du recours à l'automédication. 2011; 1-91. Available from: https://hal.archivesouvertes.fr/hal-01339418/\%0Ahttps://halshs.archivesouvertes.fr/hal-01339418v1\%0Ahttps://hal.archivesouvertes.fr/hal-01339418/document.

[21] Chiribagula VB, Mboni HM, Amuri SB, Kamulete GS, Byanga JK, Duez P, et al. Prévalence et caractéristiques de l'automédication chez les étudiants de 18 à 35 ans résidant au campus de la Kasapa de l'Université de Lubumbashi. Pan Afr Med J. 2015. 